University of Nebraska - Lincoln

DigitalCommons@University of Nebraska - Lincoln

$10-1-2021$

\title{
Crest or Trough? How Research Libraries Used Emerging Technologies to Survive the Pandemic, So Far
}

Scout Calvert

University of Nebraska-Lincoln

Follow this and additional works at: https://digitalcommons.unl.edu/libraryscience

Digitalrt of the Databases and Information Systems Commons, Data Science Commons, Digital

Commaneations and Networking Commons, and the Library and Information Science Commons

Network

Laplert, Scout, "Crest or Trough? How Research Libraries Used Emerging Technologies to Survive the Pandemic, So Far" (2021). Faculty Publications, UNL Libraries. 413.

https://digitalcommons.unl.edu/libraryscience/413

This Article is brought to you for free and open access by the Libraries at University of Nebraska-Lincoln at DigitalCommons@University of Nebraska - Lincoln. It has been accepted for inclusion in Faculty Publications, UNL Libraries by an authorized administrator of DigitalCommons@University of Nebraska - Lincoln. 


\section{Crest or Trough? \\ How Research Libraries Used Emerging Technologies to Survive the Pandemic, So Far}

Scout Calvert, Data Librarian, Michigan

State University

Edited by Mary Lee Kennedy and

Clifford Lynch

October 1, 2021 


\section{Table of Contents}

Introduction 3

How Research Libraries Used Emerging Technologies to Survive the Pandemic 5

Changed Perspectives on Crifical Emerging Technologies 8

Digitization and Digital Preservation 8

Data, Data-Intensive Research, and Open Science $\quad 10$

Online and Hybrid Learning 13

Digital Fluencies and Data Literacy 14

Student Data and Learning Analytics 16

Collaboration and Trust 17

Factors in the Adoption of Emerging Technologies 19

Ease of Use 19

Scale $\quad 20$

Cost and Convenience $\quad 20$

Speed 20

Maintenance 20

Technology Is Not Neutral _ $\quad 21$

Politics of Adoption at Institutional Level $\quad 21$

Lack of Alternatives $\quad 21$

The Comfort of Familiarity $\quad 21$

Perceptions about What a Library Is _ $\quad 22$

Conclusion: Return to Normal? $\quad 22$

Appendix: Individuals Interviewed for This Report 25

$\begin{array}{ll}\text { Endnotes } & 27\end{array}$

Crest or Trough? How Research Libraries Used Emerging Technologies 


\section{Introduction}

In the first months of the COVID-19 pandemic, it was impossible to tell if we were at the crest of a wave of new transmissions, or a trough of a much larger wave, still yet to peak. As of this writing, as colleges and universities prepare for mostly in-person fall 2021 semesters, case counts in the United States are increasing again after a decline that coincided with easier access to the COVID vaccine. Plans for a return to campus made with confidence this spring may be in doubt, as we climb the curve of what is already the second largest wave, fueled by the SARS-CoV-2 Delta variant, 18 months into the pandemic.

This report is the last in a series of reports on the role of research libraries in shaping critical technologies for use in research, learning, and libraries. Sarah Lippincott's extensive overview, Mapping the Current Landscape of Research Library Engagement with Emerging Technologies in Research and Learning, ${ }^{1}$ provides background and context for the range of digital technologies we consider in this project. The project launched with a series of interviews in fall 2019, some of which informed Lippincott's report, and the rest of which were reported in Emerging Technologies for Research and Learning: Interviews with Experts. ${ }^{2}$ That report supported a series of forecasting workshops with members of EDUCAUSE and the Coalition for Networked Information (CNI) in spring 2020, as we braced ourselves in the first wave of the pandemic. Insights generated from these workshops were shared in Future Themes and Forecasts for Research Libraries and Emerging Technologies, ${ }^{3}$ as participants described what they saw as drivers of technological adoption in the near term of one to three years.

In these reports, we described not just the technologies that attracted the attention of our expert participants, but factors in technology adoption, drawing on insights from historians and sociologists of technology. We also detected high expectations for the development of novel emerging technologies, and concomitant technological practices, with transformative potential for research, learning, and research 
libraries. In this follow-up, we returned to 11 of the participants in the interviews conducted for the project, to find out how their perspectives have changed in the year and a half since we had spoken to them, given the disruption to research and learning caused by the pandemic. (See the appendix for a list of the 11 participants.) In these new conversations, we see that optimism is retained for the same transformative technologies, but that the intense activity of these pandemic months has been largely related to adoption and refinement of existing technologies rather than innovating truly novel technological solutions to our research and learning challenges.

Remembering Shoshana Zuboff's insights that "the interplay of intrinsic qualities and human choices [about technologies] is further shaped by social, political, and economic interests that inscribe the situation with their own intended and unintended opportunities and limitations," we draw the following conclusions from these interviews:

- The pandemic tested prior commitments to networked and digital collections and services and validated those past decisions.

- The technologies that were identified in previous reports are still on the docket, but with adjusted priorities in response to conditions on the ground.

- Many small and large technologies to continue life at a distance were explored, which also generated insights into adoption under pandemic conditions that we can draw on in the future.

- As research libraries work to regain some semblance of normalcy during continued uncertainty (and after), there is a risk of retreating on important gains in the adoption of technologies and practices that benefit research and learning.

What follows is organized in three parts: first, reflections by our interview subjects on how their libraries and universities have fared in the pandemic so far, and to what factors they attribute their successes. Six socio-technological thematic areas emerged from the conversations about changed expectations for the futures of technologies-these form 
the second section of this report. Finally, we share some factors for technological adoption that were gleaned from these conversations.

\section{How Research Libraries Used Emerging Technologies to Survive the Pandemic}

In the workshops of spring 2020, participants were determined but cautious in their outlook for the near-term future for research libraries. This summer, with a year of life in the pandemic under their belts, along with better knowledge of the coronavirus and increasing availability of vaccines, interviewees expressed more confidence about the present and immediate future for universities. Research libraries on the whole seem to have risen to the challenge of the pandemic with relative success, even taking into account impacts on staff, students, and faculty.

In our respondents' experience, research libraries fared better than expected at the uncertain outset of the pandemic, due in large part to pre-existing trends toward digital collections and services that extended many libraries' presence well beyond their physical footprints. When asked how the last year went for their libraries, respondent answers included "better than expected," "it was almost trivial to go entirely online," "the shift to virtual was seamless," and "we went into the pandemic well positioned."

Research libraries were able to sustain connections to constituents and readily maintain access to most, though not all, services and resources. This was largely because research libraries have been increasing the range and depth of electronic collections and services for decades, and respondents felt that the ability to rise to the occasion shined a spotlight on the wisdom of investment in digital resources and technologies. The experiences from our interview participants were consistent with CNI's Executive Roundtable summary this spring: "the pandemic afforded academic libraries a unique opportunity to demonstrate and showcase their capabilities and offerings, and, as a 
result, campus (particularly senior leadership) perception about what the library can do and what it can deliver is shifting in a positive way." ${ }^{5}$

One respondent remarked that the "digital first" collection development policy at their institution had served them well. Another described their library's success in riding out the flip to remote as "driven by a lot of online access that we already had, plus HathiTrust" and that the library was able to deliver "in person online." Additionally, with the urgency of supporting research and learning continuity, some research libraries were able to adopt services and push the envelope on access provisions, implementing controlled digital lending and shipping print materials to displaced students. One library stood up a chat service virtually overnight-after considering it for years. Interviewees from outside their organizations' libraries shared the view that research libraries had been extremely responsive in finding new ways to make resources and support available.

Nevertheless, there were impacts on both people and service expectations. Several respondents commented on the human toll of success at their libraries, noting that library staff are struggling, though this is not unique to research libraries. Circumstances changed quickly-and changed circumstances have lasted longer than expected-straining people's ability to cope, and pushing patience, empathy, and resilience to extremes. Much of the work of the adroit pivot to remote operations and online delivery of instruction was provided by parents, frequently women who were still caring for their own children while working from home. ${ }^{6}$ And despite the now common phrases "return to work" or "return to operations," many library employees continued to work, either in the building, or at home.

Research libraries were not always able to meet their constituents' needs or expectations. The closures of buildings affected students who needed a place to study or use computers, demonstrating that students appreciate physical access to their libraries. Eighteen months ago, research libraries were gathering places for a variety of activities, places to "socialize knowledge exchange" as one expert put it. Special 
collections reading room closures deeply impacted some faculty and researchers.

While they acknowledged that research libraries had not been able to meet everyone's expectations, interview participants also noted that perhaps not all of those expectations were realistic under the circumstances. For example, some faculty demanded special access to the library or special collections, streaming of all media no matter what, or faster service delivery in stressful times. Some of those demands are indicators of what people appreciated and want from research libraries, highlight what seems arbitrary or unjustified, or show the need for change ahead. One expert captured the paradox of technical restrictions on digital materials, from the patron's point of view: "People don't know there are limited digital copies. And there aren't." Limits on digital copies are artifices-imposed by licensingthat aren't intuitive to patrons.

At the height of the pandemic, research libraries also responded to widespread calls for increased attention to anti-racism movements and efforts in the wake of protests after George Floyd was killed by police while being arrested in Minneapolis. Several interviewees mentioned this as a theme for future effort: "What attention will we give to racial justice over the long haul?" With this comes heightened awareness that racism and social justice are issues in management and organizational structures, in addition to practices in information work that were mentioned frequently in these conversations. Participants noted roles research libraries have in supporting community archive projects, and in scrutinizing data, metadata, curation, machine learning, data ownership, and other aspects of emerging and data-centric technologies that are also part and parcel of addressing social justice, equity, diversity, and inclusion. 


\section{Changed Perspectives on Critical Emerging Technologies}

In light of the starkly different world we occupy now in contrast to late 2019, we asked participants how their thinking about emerging technologies has changed since those earlier conversations. Acknowledging that the success of research libraries so far was largely due to digital technologies broadly defined, no one disputed that the pandemic was an accelerator for technologies that allowed research, teaching, and learning activities to continue at a distance and while community members were physically separated. But most innovation for research institutions happened with technologies that were already in use. As one expert put it, we should expect that the "decade ahead will be shaped more by the acceleration of existing trends than unknown emergent trends."

For research libraries, both acceleration and friction occurred at the edges of these resources and services, and point the direction for future technological, legal, and sociological work for the development and adoption of crucial technologies for research and learning. As Anna Tsing notes, friction is a necessary component of traction-and acceleration. ${ }^{8}$ Conversely, where more consensus had not been achieved, technologies that could have been useful were not deployed, or were contested, and thus did not benefit from rapid cycles of deployment and refinement.

Participant reflections coalesced on six interrelated themes pertaining to emerging technologies: digitization and digital preservation; data, data-intensive research, and open science; online and hybrid learning; digital fluencies and data literacy; student data and learning analytics; and finally, the role of collaboration and trust in meeting technological challenges that transcend a single organization.

\section{Digitization and Digital Preservation}

While no participant had felt digitization technologies and practices were not critical before the pandemic, for most, the ability of research 
libraries to meet constituent needs was closely tied to past digitization and digital access efforts, and this changed perspectives on the importance and urgency of digitization and its related practices and infrastructures.

Not only did library closures cut off access to local collections, they curtailed interlibrary lending (ILL); even libraries that maintained staffing in ILL were unable to borrow or lend to libraries that were closed. Digitized texts suddenly became central to research library lending in ways that had not been vividly imagined as an imminent possibility. Strategies that research libraries used to provide digital access to traditional print materials and to support learning and research continuity included controlled digital lending and HathiTrust's Emergency Temporary Access Service. Additionally, the Internet Archive suspended borrowing waitlists to provide emergency access to displaced students and researchers.

There was agreement among respondents that library users will now take such access for granted, expecting libraries to create digital access to both undigitized and copyrighted material. For this reason, some participants predicted that the next advances in providing digital access to library holdings will be on the legal front, with research libraries leading the way to new agreements, sometimes by taking an aggressive stance on copyright law, perhaps "through the courts" with "libraries front and center." Respondents felt that there is strong potential for transformation if many libraries band together, propelled by new expectations from constituents.

However, while digital lending supported research continuity in some domains, the pandemic "broke the paradigm" of visiting special collections reading rooms as closures of research libraries, archives, and special collections shut off access to unique research materials that are vital to the missions of research libraries. These materials could not be made available by the same routes as published materialscontrolled digital lending or interlibrary loan. Thus, respondents reappraised how digitizing special collections materials could expand 
the range of ways libraries provide access, while also creating soughtafter corpora for machine learning. While using optical character recognition (OCR) and machine learning to extract data from print and promote the discovery of digitized material is experimental and costly, events of the past year cast digitization in a compelling light, even if it will take more research and development to make good on promised potentials.

The spotlight on digitization also shines a light on digital preservation efforts, and the nightmare scenarios that await, as the quantity of digital and digitized materials expands. One interviewee asked, "Have we given up on digital preservation?" pointing to the need for strategy and policy to address the growing problem of preservation-and the budget required for the labor and infrastructure needed for preservation work. Another respondent noted that shared responsibility for digital preservation could go hand in hand with a shared print initiative, to the benefit of both endeavors.

\section{Data, Data-Intensive Research, and Open Science}

Remote work conditions under the pandemic focused attention on all research and teaching resources that could be accessed over networks, and this made the virtues of data openness and sharing even more apparent. Data for research and teaching, along with the infrastructure, tools, and expertise needed to leverage it, remained of keen interest to respondents, though for some, the enormity of the task of supporting research data and data-intensive research had come into new focus.

Data and data visualization seemed to take a bigger stage in the public square, as data dashboards related to the pandemic were built by both university research centers and county and state health departments, and news outlets leveraged publicly accessible COVID-19 data in reporting and infographics. Respondents remarked on the unprecedented degree of sharing during this time. In the urgency to learn about SARS-CoV-2 as a multifaceted phenomenon, scientists shared data, preprints, and publications across institutional and 
national boundaries, and across public and private universities and the commercial sector in ways that hadn't been seen at this pace. The phenomenon isn't limited to biomedical research and is anticipated to continue across disciplines. ${ }^{9}$

Especially early in the pandemic, health disparities were evident in widely varying mortality and morbidity rates, depending on public health resources and community health levels, which are tied to social inequality. The potential for data-intensive research to be of broad benefit was demonstrated for the public in new ways, as models of transmission, hospital utilization, and mortality regularly made the news (see, for example, the Institute for Health Metrics and Evaluation COVID-19 projections ${ }^{10}$ ). As with modeling, respondents noted the potential for predictive analytics to address health disparities and improve health care access.

Machine learning and other computational methods under that umbrella are still opportunities for research libraries and higher education, according to participants. However, developing these tools requires access to large data sets, which can pose some barriers to research and development. For research libraries, relevant data sets (within library collections) may require digitization to make them computationally available, with both initial costs and the continuing costs of preservation. Some participants were concerned that large, significant data sets are held by industry and that it is difficult for academic researchers to negotiate licensing and permissions to use owned data, which also has the effect of drawing researchers away from universities. Research libraries may have a role to play in creating or providing access to training data and to industry-owned data sets.

Another opportunity for research libraries in the machine learning space is to stake a claim in the development and ownership of discovery systems, and in supporting other efforts at automating data discovery and reuse. Not just numeric data sets, but large text corpora are needed. Natural language processing remains alluring for its potential to make connections that are latent in the scientific literature. 
Image recognition, and medical imaging in particular, stood out as a potent example of the uses for machine learning where the benefits are tangible. Image data sets, from radiographic images to handwriting and text, could boost research, for example, in OCR, and maximize the benefit of digitizing unique collections for access and discovery, as well as for collections as data.

Participants anticipated further interest and demand for cloud computing services that could expand the range of available research support offerings. The European Open Science Cloud was offered as an example of ambitious cloud-based science infrastructure that could spawn other advances in data-intensive research. Another example provided by a respondent, Emerald Cloud Lab, combines robotics and cloud computing to provide wet lab research conducted via the cloud.

One participant commented on the necessity of interoperability to data-intensive research, and noted that one hurdle to interoperability is a validated and widely adopted controlled vocabulary for the sciences. Still, FAIR (findable, accessible, interoperable, reusable) data principles are poised for wide adoption "if political incentives align, because the technology is ready enough," said one interviewee. One strategy that could help: when applications of a technology are "implemented that will be influential and ignite the imagination to try in other disciplines."

Participants also pointed to other aspects of data-intensive technology that have their attention, including bias in algorithms, fraud, and other intentionally nefarious uses for the technologies. They noted that the capacity for fraud and intentionally biased algorithms develops alongside the potential social benefit of predictive technologies. Scholarly conversations about built-in bias and uses of machine learning methods like data mining, facial recognition, and predictive analytics could be shaped by research library participation in research and development of these tools, addressing stated social justice and inclusion goals. One respondent urged research library peers not to shy away from hard conversations related to ethics and power in data practice. 


\section{Online and Hybrid Learning}

The most obvious and substantial shift in technology deployment and adoption occurred in teaching and learning, as most colleges and universities quickly moved to online learning in the first weeks of the pandemic. The forced turn to remote learning brought a culture shift and rapid cycles of development for videoconferencing and other tools for remote learning, allowing socio-technical dependencies that had slowed uptake of distance learning to be resolved. At some institutions, previously hypothetical plans to develop online and hybrid offerings were updated and brought into existence almost overnight.

As different localities implemented different coronavirus containment strategies, hybrid learning in various forms took shape in response to different sets of constraints. The mass adoption of remote instruction saw a flood of tools, apps, and widgets to support the sudden influx of students in online learning environments and provide "simulacra of the in-class experience," as one participant said. However, as another respondent noted, many web-based tools were designed for adoption at the individual level, rather than at the enterprise level, where they could be embedded into collaborative processes more fully. These tools also bypassed crucial vetting for privacy, data ownership, and accessibility.

But the successes of remote learning during the pandemic were not all about the technology, but also about practices for using the technology. One participant observed that moving online demonstrated how vital human interaction in real time is to successful teaching, learning, and collaboration, and that face-to-face interactions of any kind are precious resources.

The move to remote instruction also put pressure on assessment. Some teaching and assessment practices that worked in classrooms and lecture halls don't translate readily to the online environment without costs to consent, privacy, and questions of data ownership. The shift to remote instruction highlights already existing debates about labor, class size, testing, and other assessments, as students push back 
against technologies they feel are invasive and others whose bias is documented (see below, on privacy).

Now that they have experienced how interaction that makes for fulfilling learning can be enabled by new technologies, more people are compelled by the potentials for distance learning. Respondents noted new opportunities for higher education that had not been as realistic before. One opportunity area is the development of platforms that allow teaching, learning, and collaboration to "scale up, bending cost curves," in the words of one interviewee, while lowering barriers to access to education. Another opportunity noted by a respondent is to leverage the expansion of online learning to provide affordable and quality GED and college-level education to incarcerated people. Continued reliance on these tools may result in pressure to improve and enhance online education, with potential for addressing equity in access to higher education.

\section{Digital Fluencies and Data Literacy}

Another impact of the flight to remote instruction was to put pressure on the digital fluencies of both faculty and students, as new tools for mirroring classroom experiences proliferated. One faculty member remarked that remote instruction went better than expected, despite skepticism, in large part due to the forbearance and willingness of students to "try new things." However, the compulsory use of untested online tools in high-stakes systems put the spotlight on digital and data practices that people often ignored previously.

As one respondent noted, students began to ask, "What are my rights as a consumer in how my data is protected?" as they pushed back on testproctoring services that felt invasive or biased. Respondents related the concerns of their students who, for example, could not meet proctoring requirements to be alone in a room, or experienced the invasion of privacy involved in having to show a panoramic view of one's living space. Others noted that facial-detection software was calibrated to lighter faces, building racial bias into systems. Remote learning has 
heightened awareness of data- and algorithm-powered systems that are much more pervasive and sophisticated than they were when the conventional wisdom that privacy is dead arose.

Another crucial component of digital fluency is understanding how data is created, disseminated, analyzed, and applied in everyday life and the technological and economic systems we interface with. Most people accept that data appropriate to specific uses and needs will be maintained for those purposes, in ways appropriate to those uses, for example financial and health records. While proper handling of data has typically traveled under the label "data ethics," this framing may be of limited use in conversations about power that the growing scholarship on data sovereignty and algorithmic bias provoke, in the view of one faculty member, where power-laden issues like racialization, class, gender and sexuality, language, and geography are at stake.

Hand in hand with digital fluencies, participants agreed that data literacy is still a crucial area to leverage for library work, student success, and research support, and that research libraries may be in position to address gaps, across disciplines and levels of preparation for college. One respondent observed that most available tutorials are either designed for younger audiences, and thus infantilizing to college and graduate students, or have a steep learning curve and assume a disciplinary background in the sciences. Another remarked that it will take deeper competencies for librarians to improve data-literacy instruction, as well as subject content that is sensitive to student major and background. 


\section{Student Data and Learning Analytics}

Questions about privacy, ethics, and power that are at play in the online test-proctoring tools that were promoted during the pandemic are present in areas of research and learning as well, and these were highlighted in conversations about learning analytics. Though there is momentum in higher education to develop and adopt enabling frameworks, learning analytics was one data-centric emerging technology that did not see rapid deployment or advancement under pandemic pressure-cooker conditions. Where systems had not already been implemented, faculty were challenged to get a feel for student well-being as they had through their presence in physical classrooms. Without developed processes for the use of student data in learninganalytics initiatives, some universities were unprepared to ask and answer questions about student success that might have been afforded by massive uptake of online learning and the attendant creation of digital trace data.

Familiar tools for assessment were harder to use in online environments, one respondent noted, often because they relied on ethnographic and qualitative methods like focus groups that could no longer be convened in person, and because tools that weren't seen as mission critical had to be jettisoned to make room for other urgent work. Many more students joined the ranks of the already invisible online students. Without the processes needed to enable careful and appropriate use of student data by instructors, researchers, and university administrators, it is challenging to develop research questions to systematically diagnose what is happening for students during the pandemic, what resources they are connected to, or why they leave or stay in college. This is even more damaging from an equity perspective, because of the need to address factors that support the success of students from underrepresented groups.

One respondent noted that privacy seems to be an all-or-nothing proposition for research libraries, which poses a barrier to their active participation in student-success initiatives. The privacy discussions 
taking place in other spaces in higher education may be more nuanced than they get credit for, taking into account different kinds of data with different privacy needs, to ensure research uses that do not involve risks to students. There is a concern that by avoiding exploration of ethical, beneficial, and appropriate uses of data, research libraries leave a vacuum that will be filled by industry developers without the same commitment to privacy and confidentiality entailed in intellectual freedom. Understanding the different kinds of data about students and how they are used by faculty and administrators is necessary to enter conversations that could resolve issues for research library participation, and in turn allow development of tools that account for privacy, ethics, and power differentials that also help explain how libraries support learning. As one respondent put it, the goal is "datainformed pedagogy, not data-driven pedagogy." Research libraries that are closed to this discussion may not be aware that their own privacy policies haven't kept up with the systems that create, use, store, or transmit data.

\section{Collaboration and Trust}

A nontechnical factor in the ability to adopt and develop emerging technologies for research and learning is collaboration. Collaboration across scale continues to be understood as essential to advancing crucial technologies for research libraries.

For some crucial technologies to advance, collaboration is requisite. Respondents recognized the potential for partnership in the development of data-sharing and data-research infrastructure, work around FAIR data standards, and collaborations designed to address the scholarly communications landscape, from transformative agreements to open scholarly infrastructure. Other projects that would allow research libraries to leverage scale are advancing controlled digital lending, shared print repositories, shared digital preservation and digital-preservation infrastructure, and a national finding aid project to allow research and discovery of unique collections. 
Open access was a frequently mentioned area for coordination and cooperation. Respondents put stock in the potential for transformative agreements and for expanding consortium efforts to diversify collections and membership. One respondent asked if open access and transformative agreements are really the unaffordable luxuries that they are implied to be, or if continuing to pay for traditional content will also cause research libraries to miss the opportunity to seize the momentum of the pandemic. Investing in new initiatives requires disinvestment in activities that had been seen as priorities in the past. For example, some respondents noted that applying a cost-recovery model for things like university press publication, which could be seen as mission critical for scholarly communication, hinders the expansion of open access.

With a nod to the role research libraries play in academic success for students, learning analytics is another area where collaboration on the part of research libraries was viewed positively. The Caliper Analytics specification is a data model for use in academic information systems that is also a potential site for working together, reflecting the capacity for research libraries to step into the conversation as trusted partners, shifting and directing conversations about consent, ethics, power, and ownership of student data.

Within institutions, collaborating to support student success, information literacy, and digital fluencies remains essential. Participants suggested that libraries could also look for partners to develop a data-science curriculum that is true to the interdisciplinary core of data science, drawing on computer science, statistics, and the humanities, in addition to other domain knowledge. One respondent pointed to the need for librarians to build expertise in data and data tools to maintain trust for classroom partnerships. Careful collaboration could allow library-coordinated data-science instruction to benefit from instructors and projects from industry partners, especially in light of the pace of development in industry. Several respondents pointed to collaborations between their campus library and IT departments in swiftly deploying and supporting technologies 
and services in the shift to remote. Building on this relationship to support research data and infrastructure, perhaps through joint appointments in research IT and libraries, could advance data science and research-data management.

Finally, navigating partnerships involves recognizing the different drivers for each organization or unit. For research institutions, pooling investments involves understanding that the stakes may still be different for otherwise similar organizations. Industry's revenuedriven mission will require the most translation in partnerships.

\section{Factors in the Adoption of Emerging Technologies}

The pandemic put pressure on technologies that allowed knowledgecentric activities-teaching, learning, research, and information services-to proceed at a distance. This demonstrated insights illustrated in the previous ARL-CNI-EDUCAUSE reports that technological adoption is always a sociological phenomenon, and, in Kranzberg's words, "nontechnical factors take precedence" in technology decisions. " The technologies that saw intense use and development weren't new; the circumstances had changed enough to eliminate barriers to their use, including shifting attitudes about online education and electronic books. Participants identified the following factors in technological adoption.

\section{Ease of Use}

Tool adoption is more likely when technologies are easy enough for people to explore and navigate on their own. One respondent noted that technological work is frequently about creating complexity then hiding that complexity from users, so that they experience tools that are ready to hand. 


\section{Scale}

The search for a "neutral" solution hinders the adoption of a de facto solution. Perfection is the enemy of scalability in technological adoption. Elevating common standards will facilitate interoperability and the development of library platforms that can gain critical mass for adoption at scale.

\section{Cost and Convenience}

During the pandemic, people experienced the time- and cost-savings of videoconferencing, not just for teaching and learning and for staff meetings, but for conferences and professional association meetings. Some respondents anticipated that the balance will tip in favor of continued electronic meetings, at least some of the time, with potential benefits to the environment and work-life balance. Those benefits may be somewhat diminished by the costs of managing the explosive growth of digital assets produced by those meetings.

\section{Speed}

People want things fast and have become used to accessing digital things immediately. The hard work libraries did to make that possible over decades is not always apparent to users and campus administrators. This will put pressure on libraries to deliver as quickly as commercial competitors, and could make different approaches appear newly possible.

\section{Maintenance}

The labor and cost of maintaining technological tools and systems is significant. The issue of maintenance in technological systems is starting to get more attention (see, for example, The Maintainers ${ }^{12}$ ). Will libraries invest in maintenance? Are people going to be paid and rewarded to maintain the systems-and their skill sets? 


\section{Technology Is Not Neutral}

As disability-rights advocates noted, accommodating different workplace needs was possible before the pandemic-the pandemic just made it necessary for large numbers of workers. As library science has been learning, classification and collecting practices are not neutral, and our technological choices always encode values.

\section{Politics of Adoption at Institutional Level}

One organization's long-shelved plan for chat support was dusted off and implemented overnight, overcoming institutional inertia. When tools were used ad hoc in online courses, it implied that tools had university approval and had been vetted. For the sake of students, research libraries and campus IT departments may want to investigate the privacy and accessibility of these tools and provide or recommend better ones.

\section{Lack of Alternatives}

More clickstream data is available because interaction is happening online. Distance learning could influence the adoption of learning analytics, because instructors have fewer cues to understand whether and how online learning is working. Being active in this space or other spaces could offer research libraries a chance to shape these technologies before the die is cast by commercial entities with different priorities.

\section{The Comfort of Familiarity}

Despite the relative success of remote operations, people understandably miss relationships and habits from before the pandemic. At universities, the allure of the return to normal is in part because administrators miss the predictability: "we know what normal is and what normal costs," as one said. But the pull toward the known and familiar is a pull away from building on crucial advances that could allow research libraries to positively enact their missions. 


\section{Perceptions about What a Library Is}

The last factor in adoption is a general perception of what a library is, to faculty both outside and inside the library. A paradox of effective library work is its invisibility. As Bowker and Star note, "Good, usable systems disappear almost by definition." ${ }^{13}$ When constituents-or staffunderstand the library to be primarily about books, it's easy to ignore work conducted by library staff in the background to ensure access to research resources. To hold position as a place where essential work happens-be it in regard to student success, teaching and learning, data literacy, or research support-library staff must be perceived as reliable guides to new technologies and technological practices, in addition to subject experts.

\section{Conclusion: Return to Normal?}

Undoubtedly, the research and learning landscape has changed as though by a 100-year flood. As universities make plans-and contingency plans-for a return to campus for the fall 2021 semester, they are working with many moving parts, including vaccination requirements and mask mandates, new and emerging COVID variants, predictions for localized outbreaks of SARS-CoV-2 as seasons and congregation patterns change, and the needs and desires of staff and faculty to work remotely for reasons ranging from child care to productivity to health.

A key factor for some universities is the role campus life plays in the undergraduate experience. Universities where physical presence is a key part of the student experience may anticipate that students will return to campus without hesitation; one respondent highlighted a large increase in applications for the upcoming school year. Another expressed cautious optimism about campus presence and more inperson courses than last year. The pull to get back to normal-whatever counts as normal these days-is strong.

Other universities may find less interest in a return to campus on the part of students, especially those who commute, now that a compelling 
alternative has been shown to work, and even demonstrated that some courses and programs are better delivered online, using tools turbocharged during the pandemic, than in person. But all interviewees expected that online and hybrid learning options aren't going away and will shape expectations from students about course format options that allow flexibility-and perhaps, affordability.

The workforce is a different matter, and whether that presents as an "administrative nightmare," as one interviewee put it, or an opportunity may depend on the organization or individual. One respondent explained that the turn to videoconferencing had a positive impact on distributed teams: "We're more together, more connected now." Videoconferences drastically reduce the cost, inconvenience, and environmental consequences of bringing remote coworkers together in the same place. New strategies for the accessible workplaces that inclusion demands are undeniably available to research libraries now. Some organizations may recruit for remote positions to generate a more competitive candidate pool. It is possible that remote work may still be necessary for reduced density and to respond to localized outbreaks; other work may be able to take place on campus easily, but whether staff and faculty are willing, now that productive remote work has been proven in practice, is up in the air. A crucial factor is whether childcare will be available and affordable, and if school-age children will be able to attend school in person.

In July 2021, new cases of SARS-CoV-2 began rising again, propelled by the infectiousness of the Delta variant, after declining to their lowest level in the United States since March 2020. ${ }^{14}$ About 52\% of the population in the US has been fully vaccinated, or $61 \%$ of eligible people, according to the US Centers for Disease Control and Prevention (CDC) as of August 26, 2021. ${ }^{15}$ Globally, the pandemic persists, and at this time vaccine supply and distribution are insufficient to the world population. Experts warn that we may endure waves of smaller, localized outbreaks until the virus becomes endemic and COVID vaccines become as routine as seasonal flu vaccines. Other variants may arise that are more lethal, more transmissible, or both. 
The success of remote operations will put pressure on universities and research libraries to review their physical footprints, giving up leases and office space. Research libraries have an opportunity to think about what is most important to provide in the spaces they maintaintechnologies, resources, and experiences that may be challenging to provide remotely, that allow scholarship and knowledge production to be expressed as the social activities that they are. The research library is also a physical destination, as well as the cluster of people, policy, and infrastructure that provides resources and support digitally. Remote operations demonstrated the capacity of research libraries-and their staff-to do this well. But a physical base for operations remains necessary.

Still, despite acknowledgement that everything has changed, participants expressed concern that giving in to the pull of normalcy risks reversing course on changes that improved prospects for library initiatives. This pull will be especially strong for research libraries, where physical space has been the central, traditional, and remembered experience for patrons.

As we wrap up this project, the conclusion is unavoidable: adoption of technologies is only ever partly about the technology-it is also about the social contexts in which technologies arise and are deployed. Attention paid to the social circumstances into which technologies emerge or are adopted has continued to reveal concerns about bias in the data and algorithms that power technologies that are increasingly ubiquitous and unavoidable. Devoting this attention is no longer new in research libraries, and this important strain of technology analysis can be pursued in many research library practices, including classification, metadata, organizational development, and digital projects like community archiving.

The COVID-19 pandemic put the adoption and development of some technologies on high heat, while others remained on simmer. Research libraries that fared well did so in large part due to the steady expansion of digital offerings provided online in the years or decades prior to the 
pandemic. As we head up another wave of transmission, uncertainty remains. Research libraries can stay ready and continue efforts to identify needed services and resources to enhance and develop-which will also meet expectations that changed during the "new normal." As the yearning to return to campus grows, research libraries have an opportunity to make conscious choices about which parts of "normal" to return to-and which parts of the "new normal" to embrace.

\section{Appendix: Individuals Interviewed for This Report}

Kristin Antelman

University Librarian

University of California, Santa Barbara

Philip E. Bourne

Stephenson Dean, School of Data Science

Professor of Data Science

Professor of Biomedical Engineering

University of Virginia

Kevin M. Guthrie

President

ITHAKA

James L. Hilton

Vice Provost for Academic Innovation

University Librarian and Dean of Libraries

Arthur F. Thurnau Professor and Professor of Information

University of Michigan

Michele L. Norin

Senior Vice President and Chief Information Officer

Rutgers, The State University of New Jersey 
Megan Oakleaf

Associate Professor

Director of Online Student Engagement

School of Information Studies

Syracuse University

Miriam Posner

Assistant Professor, Information Studies \& Digital Humanities

Department of Information Studies

University of California, Los Angeles

MacKenzie Smith

University Librarian

Vice Provost of Digital Scholarship

University of California, Davis

George Strawn

Scholar

Board on Research Data and Information

National Academy of Sciences, Engineering, and Medicine

Jenn Stringer

Associate Vice Chancellor for IT and Chief Information Officer

University of California, Berkeley

Keith Webster

Dean of Libraries

Director of Emerging and Integrative Media Initiatives

Carnegie Mellon University 


\section{Endnotes}

1. Sarah Lippincott, Mapping the Current Landscape of Research Library Engagement with Emerging Technologies in Research and Learning, ed. Mary Lee Kennedy, Clifford Lynch, and Scout Calvert (Association of Research Libraries, Born-Digital, Coalition for Networked Information, and EDUCAUSE, 2021), https://doi. org/10.29242/report.emergingtech2020.landscape.

2. Scout Calvert and Mary Lee Kennedy, Emerging Technologies for Research and Learning: Interviews with Experts, ed. Clifford Lynch and John O'Brien (Association of Research Libraries, Coalition for Networked Information, and EDUCAUSE, March 2020), https:// doi.org/10.29242/report.emergingtech2020.interviews.

3. Scout Calvert, Future Themes and Forecasts for Research Libraries and Emerging Technologies, ed. Mary Lee Kennedy, Clifford Lynch, and John O'Brien (Association of Research Libraries, Coalition for Networked Information, and EDUCAUSE, August 2020), https:// doi.org/10.29242/report.emergingtech2020.forecasts.

4. Shoshana Zuboff, "In the Age of the Smart Machine," accessed September 2, 2021, https://shoshanazuboff.com/book/books/inthe-age-of-the-smart-machine/.

5. "Post-Pandemic Strategic Planning: Challenges and Approaches, Report of a CNI Executive Roundtable Held March 2021," Coalition for Networked Information, April 2021, 14, https:// www.cni.org/wp-content/uploads/2021/04/CNI-Post-PandemicPlanning-ER-Report-s21-Public-FINAL.pdf.

6. National Academies of Sciences, Engineering, and Medicine, "Short-Term Strategies for Addressing the Impacts of the COVID-19 Pandemic on Women's Workforce Participation," The National Academies Press, 2021, https://doi.org/10.17226/26303. 
7. Brad Wheeler, "The Post-COVID Decade: Overcapacity, Innovation, and Consolidation" (slide presentation shared with the author, August 24, 2021).

8. Anna Lowenhaupt Tsing, Friction: An Ethnography of Global Connection (Princeton, NJ: Princeton University Press, 2005).

9. National Academies of Sciences, Engineering, and Medicine, "Data in Motion: New Approaches to Advancing Scientific, Engineering and Medical Progress: Proceedings of a Workshop-in Brief," The National Academies Press, 2021, https://doi.org/10.17226/26203.

10. "COVID-19 Projections," Institute for Health Metrics and Evaluation, accessed September 2, 2021, https://covid19. healthdata.org/.

11. Melvin Kranzberg, "Technology and History: 'Kranzberg's Laws," " Technology and Culture 27, no. 3 (1986): 550, https://doi. org $/ 10.2307 / 3105385$.

12. "Information Maintainers," The Maintainers, accessed September 2, 2021, https://themaintainers.wpengine.com/informationmaintainers/.

13. Geoffrey C. Bowker and Susan Leigh Star, Sorting Things Out: Classification and Its Consequences (Cambridge, MA: MIT Press, 1999), 33.

14. "Coronavirus in the US: Latest Map and Case Count," New York Times, updated September 7, 2021, https://www.nytimes.com/ interactive/2021/us/covid-cases.html.

15. "COVID Data Tracker Weekly Review: Interpretive Summary for August 27, 2021," US Centers for Disease Control and Prevention, accessed September 2, 2021, https://www.cdc.gov/ coronavirus/2019-ncov/covid-data/covidview/index.html. 


\section{ASSOCIATION OF RESEARCH LIBRARIES

Association of Research Libraries

21 Dupont Circle, NW

Suite 800

Washington, DC 20036

T 202.296.2296

F 202.872.0884

ARL.org

pubs@arl.org

This work is licensed under a Creative Commons Attribution 4.0 International License.

(c) 1 